\title{
DESAFIOS PARA UMA TRANSFORMAÇÃO PEDAGÓGICA: AMBIENTES EDUCATIVOS CRIATIVOS E INOVADORES
}

\author{
Maria Regina Teixeira Ferreira Capelo \\ SRE, CLEPUL/Polo da Madeira \\ Pós-doutoranda UNIFOR \\ m.regina.capelo@gmail.com \\ John Miguel Costa Varela \\ SRE, CLEPUL/Polo da Madeira \\ jmcvarela@gmail.com \\ Noemí Serrano-Díaz \\ Universidad de Cádiz \\ noemi.serrano@uca.es \\ Maria Helena de Agrela Gonçalves Jardim \\ CAPES/FUNCAP-UNIFOR \\ Universidade da Madeira \\ hjardim@staff.uma.pt
}

Fecha de Recepción: 28 Marzo 2019

Fecha de Admisión: 30 Abril 2019

\section{RESUMO}

A acelerada expansão e disseminação das tecnologias digitais tem vindo a potenciar a criatividade e a inovação pedagógica. Por sua vez, criatividade e inovação são o capital social hodierno. A educação tem um papel fundamental neste processo por ser o motor do desenvolvimento económico, social e humano e para o futuro das sociedades. Além disso, o mundo evoluiu com a tecnologia, assente em duas aliadas interdependentes, a criatividade e a inovação. Este estudo tem como objetivo refletir sobre a importância dos ambientes criativos e inovadores, potenciadores da transformação pedagógica e do progresso social. Metodologicamente valeu-se de uma pesquisa bibliográfica recolhida em repositórios científicos eletrónicos de livre acesso a partir dos descritores ambientes educativos, criatividade, inovação e tecnologias. Os resultados consistentes com a literatura sugerem que a tarefa é requerida aos professores para que concebam ambientes propícios ao desenvolvimento das habilidades que reflitam abertura, enfrentamento do risco, pensamento crítico, flexibilidade, sensibilidade, questionamento e não conformidade, cujo impacto direto é fundamental no processo de ensino-aprendizagem, na vida futura dos alunos, no desenvolvimento humano e no progresso social.

Palavras chave: ambientes educativos; criatividade; inovação; tecnologias 


\title{
DESAFIOS PARA UMA TRANSFORMAÇÃO PEDAGÓGICA: AMBIENTES EDUCATIVOS CRIATIVOS E INOVADORES
}

\begin{abstract}
Challenges for a pedagogical transformation: creative and innovative educational environments. The accelerated expansion and dissemination of digital technologies has been promoting creativity and pedagogical innovation. In turn, creativity and innovation are today's social capital. Education plays a key role in this process as it is the engine of economic, social and human development and the future of societies. In addition, the world has evolved with technology, based on two interdependent allies, creativity and innovation. The purpose of this study is to reflect on the importance of creative and innovative environments, which are an enabler of pedagogical transformation and social progress. Methodologically, it was used a bibliographical research collected in electronic repositories of free access from the descriptors educational environments, creativity, innovation and technologies. The results consistent with the literature suggest that the task is required of teachers to design environments that are conducive to the development of skills that reflect openness, coping with risk, critical thinking, flexibility, sensitivity, questioning and nonconformity, whose direct impact is fundamental to the process in the future life of students, in human development and in social progress.
\end{abstract}

Keywords: educational environments; creativity; innovation; technologies

\section{INTRODUÇÃo}

A globalização, a evolução tecnológica e a mudança constante têm transformado os processos económicos, culturais e sociais em todo 0 mundo. Carvalho (2002) refere-se à globalização como algo que fascina e inquieta, que surge como última afirmação do colonialismo e que é vista como uma dimensão nova de esperança, como uma utopia a realizar-se. É a expressão da extraordinária capacidade tecnológica do homem. A informática, a circulação instantânea de mensagens e todo um universo de realização tecnológica aparece como a própria criação humana. Esta evidência, em termos reflexivos, antropológicos, epistemológicos e, naturalmente, pedagógicos coloca questões à sociedade que remetem para a emergência de um novo paradigma de escola. Este tipo de transformações imprime um novo rumo no papel da escola, o lugar onde se concretiza a relação pedagógica, onde a aprendizagem só se realiza em situações que tenham sentido para o sujeito (Canário, 2005).

Na sociedade globalizada do ciberespaço, as tecnologias puderam automatizar tudo, exceto 0 humano, ou seja, a subjetividade, a criatividade, o espaço íntimo. Nesse aspeto, as potencialidades da sociedade global, passam pela culturalização das pessoas, pela sua formação como indivíduos detentores e conscientes de uma subjetividade, capazes de apropriação criativa, ou seja, de recontextualização das mensagens (Carvalho, 2002). É nesta conjuntura que a escola intervém na construção dos indivíduos como pessoas.

A escola criativa que almeja formar e transformar, busca desenvolver e valorizar os potenciais criativos, o empreendedorismo, a importância do desenvolvimento humano a partir do seu contexto, visando o bem individual, social e planetário (Sousa \& Pinho, 2016). A relação criativa com 0 conhecimento, surge pelo cruzamento da dupla vertente curricular, extracurricular, constituindo a grande riqueza da escola cultural, ou seja, com os espaços disciplinares, os espaços de criatividade e, mais ainda, o da sua contínua conexão (Carvalho, 2002). Esta será a única forma de permitir que os estudantes se apropriem do saber, apropriem criativamente de todo o saber, em conformidade com os pressupostos do ciberespaço que é um espaço de saber (Carvalho, 2002). Segundo Souza e Pinho (2016), outros autores defendem um rompimento com o paradigma conservador e a criação, nas instituições escolares, de novos referenciais teóricos que por oposição ao trabalho individual e ao saber fragmentado, valorizem a busca e interligação de saberes e a produção de conhecimentos, bem como os potenciais criativos individuais e coletivos. 
A educação é o motor do desenvolvimento económico, social e humano das regiões (SilvaGuerra, 2017), mas a sua qualidade assenta no papel determinante do professor (OCDE, 1999; SilvaGuerra, 2017) como profissional detentor de formação técnica e cientifica pós-graduada. SilvaGuerra (2017) defende a otimização e valorização dos professores que laborem em instituições educativas de alto nível, com tecnologia avançada e em ambientes propícios à criatividade e à inovação, aumentando o seu estatuto socioeconómico, porque são eles, como intelectuais transformadores (Giroux, 1997), comprometidos com a mudança e progresso social, através de atividades pedagógicas criativas e inovadoras, as peças fundamentais para 0 desenvolvimento humano.

Esta pesquisa, assente em referencial teórico, aborda a criatividade e a inovação docente como aliadas inseparáveis e interdependentes para a mudança educacional, tendo como objetivo maior, refletir sobre a importância dos ambientes criativos e inovadores potenciadores da transformação pedagógica e do progresso social.

\section{CRIATIVIDADE E INOVAÇÃO}

Falar em criatividade, frequentemente, conduz à definição de processos criativos como algo ligado a atividades diletantes e inúteis (Cavalcanti, 2006). Do verbo latino crear, que significa "dar existência a", "gerar", "originar", "produzir", "instituir", "fundar", "ser o primeiro a fazer" (Grande Enciclopédia Portuguesa Brasileira, VIII, p. 36), ou "capacidade para encontrar novas soluções a um problema", "sinónimo de função inventiva", "intuição", "descoberta" e até, por vezes, de "inteligência". Porém, "estas capacidades, embora ligadas a processos cognitivos, são essencialmente independentes das diferenças individuais em inteligência geral" (Grande Enciclopédia Portuguesa Brasileira, Atualização, III, p. 554). Trata-se de um constructo complexo, multifacetado e pouco estudado, sendo inquestionável a sua importância na sociedade que solicita produtos criativos no mundo educacional em que a criatividade deve ser promovida (Oliveira \& Alencar, 2008). Neste âmbito, Gardner (1984) apresenta uma visão de criatividade que difere muito pouco do seu conceito de inteligência. Para o referido autor, o indivíduo criativo é uma pessoa que resolve problemas com regularidade, elabora produtos ou define novas questões num campo que ao principio é considerado novo, mas que no final chega a ser aceite num contexto cultural concreto.

0 vocábulo criatividade transporta na sua etimologia a dimensão de nascimento e transformação (Cavalcanti, 2006), tornando-se difícil afirmar com precisão o seu significado e elaborar uma definição consensual que 0 ilustre. Neste âmbito, Riley (2015) define criatividade como a habilidade de gerar novas ideias, bem como a capacidade de pensar de forma original ou como a capacidade de criar uma abordagem única para criar algo. Argumenta que, em geral, indivíduos não criativos, pensadores convergentes, usam apenas o conhecimento e lógica para responder a solicitações e que as pessoas criativas são pensadores divergentes, tendem a ter um leque mais diversificado de interesses e a se importar mais por ideias filosóficas, abstratas e fora dos parâmetros considerados normais ou da caixa (outside the box ideas...).

Ao falarmos de criatividade, estamos perante uma potencialidade humana (Nuñez \& Santos, 2012), ou seja, uma dimensão da conduta humana extremamente complexa, que envolve os processos mais básicos como a perceção até aos mais complexos, como o pensamento analógico ou a solução de problemas e desde os processos cognitivos aos de natureza afetivo-motivacional (Romo, 2008). Portanto, um dos aspetos da criatividade é o da complexidade cognitiva (Riley, 2015) ao envolver a interação de habilidades cognitivas, estilos de pensar, caraterísticas de personalidade e elementos ambientais e culturais (Wechsler, 2004).

Debruçando-se sobre o fenómeno Rhodes (1961) identificou quatro vertentes representadas nos 4 P's da criatividade, "the person", "the process" "the product" e "the press", não encontrou 
uma definição universalmente aceite, mas ofereceu uma nova forma de pensar sobre a mesma (Min \& Gruzka, 2017). A palavra criatividade nomeia o fenómeno através do qual a pessoa comunica um novo produto estando implícito o conceito, bem como 0 ambiente, no processo mental (Rhodes, 1961). Todavia, definições recentes de criatividade destacam mais um aspeto, o valor do produto (Min \& Gruzka, 2017). Simonton (1995) acrescentou "a persuasão" como um potencial dos líderes uma vez que, estes, podem influenciar os outros. Por isso, a criatividade pode ser vista como uma forma de liderança. Runco (2007) também contribuiu para o estudo da criatividade ao tentar reorganizar o constructo numa estrutura hierárquica ao procurar distinção entre o potencial criativo em oposição ao desempenho criativo. 0 potencial criativo é composto pelo processo criativo, pela pessoa e pela influência do ambiente, enquanto o produto criativo e a persuasão pertencem à categoria de desempenho (Min \& Gruzka, 2017), sendo 0 ato criativo caraterizado pela originalidade, flexibilidade, produtividade, elaboração, análise, síntese, abertura mental, comunicação, sensibilidade para os problemas e redefinição (Souza \& Pinho, 2016).

Tocados pela ideia inspiradora de ver a criatividade a partir dos 4 P's, Min e Gruszka (2017) estudaram o modelo de criatividade de 4P's proposto por Rhodes (1961), desde as diferentes perspetivas, em diversos domínios, incluindo a educação, o negócio, a engenharia, cuja questão principal consiste em determinar como estimular a criatividade, ativando cada um dos seus componentes. Parece que, na perspetiva de Min e Gruzka (2017), embora ainda estejamos longe do entendimento completo da noção de criatividade, seus domínios e pré-condições, a criatividade não proporciona, apenas, satisfação decorrente da ampliação do conhecimento, mas também possíveis consequências pragmáticas. 0 modelo de criatividade do 4P's preconizado por Rhodes (1961) pode ser efetivamente usado para orientar a atenção do pesquisador para aprender mais sobre como estimular a criatividade em diferentes contextos, por exemplo, melhorar o ensino para a criatividade, facilitar a solução de problemas em qualquer domínio do quotidiano, melhorar o desenvolvimento econômico, etc. Por sua vez, as situações adversas são estímulos para mudanças criativas, aprendizagens e transformações da realidade. Caso a postura do sujeito ou instituição, nesse processo, seja de enfrentamento e criatividade, o que é elaborado, quase sempre, é inovador (Suanno, 2013). Criar e inovar incidem sobre conjunturas contextuais diversas que envolvem a vida humana (Souza \& Pinho, 2016). A criatividade precede a inovação, pois, 0 ato de inovar requer partir do pressuposto que uma ideia criativa poderá materializar-se em algo novo, convertendo-se num produto, numa prática ou numa ação inovadora (Souza \& Pinho, 2016; Wechsler, s/d). Isto é, após surgir uma ideia criativa cabe à inovação o papel de transformá-la em algo concreto e desejável (Souza \& Pinho, 2016), sendo que o processo inovador tem como constituinte a própria inovação.

Inovação, do latim innovare, innovatio, significa fazer inovações, introduzir qualquer novidade no governo, nas leis, numa crença, num costume, numa ciência, numa indústria, etc. estrear, lançar, produzir, encontrar um novo processo, renovar (Grande Enciclopédia Portuguesa Brasileira, XIII, p. 841). 0 termo tem sido comumente utilizado nos nossos dias associado à ciência e à tecnologia. Porém, a acumulação de ciência e tecnologia, por si só, não garante 0 aparecimento de uma inovação (Wechsler, n/d). Esta exige ser precedida pela criatividade que possibilitará que os avanços científicos num determinado domínio sejam transformados ou aperfeiçoados em algo original e com impacto para a sociedade, caso contrário teremos apenas a replicação de um conhecimento existente, o que não carateriza a existência de uma inovação.

Suanno (2013) realça que em situações adversas, um projeto realizado com criatividade, tem a possibilidade de gerar algo inovador, mas também se pode verificar que existe diferença entre criar e inovar, ao mesmo tempo que se complementam. Dissertando sobre o processo diferenciador e interdependente da criatividade e da inovação, Rajadel (2012) esclarece que todos podemos gerar 
ideias simples ou complexas, mas não devemos confundir estes constructos, porque a inovação é a capacidade organizativa de transformar uma boa ideia num produto, serviço ou processo, aos quais se deve acrescentar o fator êxito, naquele cenário contextual concreto. Existe diferença entre criar e inovar e, ao mesmo tempo, um fenómeno complementa 0 outro. 0 ato de inovar nasce da necessidade de mudança e da necessidade de encontrar a resposta mais adequada para essa mudança.

Correia (1991), afirma ser habitual a utilização indiscriminada do vocábulo, pelo que procurou circunscrever o conceito quando afirma que inovação é uma mudança deliberada e conscientemente assumida, visando objetivos bem precisos, designadamente, a melhoria do sistema e 0 aumento da eficácia no cumprimento dos objetivos. Portanto, inovar é um processo planificado que prossegue objetivos compatíveis com os do sistema, cujo intento é a produção de resultados positivos (Silva-Guerra, 2017). Esse processo requer uma rutura paradigmática que permita reconfigurar 0 conhecimento, ultrapasse a introdução de novidades, inclusive as tecnológicas, transcendendo as regularidades e produzindo novos conhecimentos e novas fronteiras (Souza \& Pinho, 2016). 0 que se deduz é que a criatividade tem sido entendida como a conceção de novas ideias sem existir preocupação sobre a utilidade ou valor económico das mesmas, enquanto a inovação surge como um termo muito utilizado nas organizações para enfatizar e promover a comercialização de um novo produto que possa ser utlizado por uma vasta quantidade de pessoas. Neste sentido, podem ser considerados como inovadores os processos ou estratégias que promovam ganhos, benefícios ou produzam impactos sociais nas mais diferentes áreas do saber, de forma criativa.

Certa de que a criatividade e a inovação envolvem decisões de grande impacto para a melhoria da qualidade de vida nos múltiplos domínios da sociedade hodierna, Wechsler (n/d) desenhou um modelo a integração que deve existir para que a criatividade se converta em inovação. Esta depende não só de esforços criativos individuais, mas também da interação criativa dos membros de equipa multidisciplinar e dos elementos ambientais e culturais que facilitam o seu aparecimento, como educação e conhecimento, clima organizacional ou institucional, investimento em processos ou produtos criativos e inovadores, valores e políticas de incentivo à inovação dentro do país. Nesta linha de ideias e a partir da observação de países que alcançaram altos níveis de desenvolvimento, a Organization for Economic Co-Operation and Development (OECD, 2009) recomenda um grande investimento em educação criativa, necessário para que se consiga mentes capazes de inovar e assim se alcançar os níveis de desenvolvimento desejáveis equitativos entre países.

A inovação educacional é considerada uma componente da competência profissional do professor, não apenas como uma definição abrangente e multidimensional, mas sim como uma série de intervenções, decisões, processos, com algum grau de intencionalidade e sistematização, que contribuam para modificar atitudes, ideias, culturas, conteúdos, modelos e práticas pedagógicas e, por sua vez, introduzir novos projetos e programas, matérias curriculares, estratégias de ensino e aprendizagem, modelos didáticos e uma forma de organizar e gerir o currículo, a escola e a dinâmica da aula (Carbonell, 2001). A inovação é, assim, entendida como um instrumento de resposta aos contextos educativos incertos da hodierna sociedade em mudança, exigindo do professor que exercite as suas capacidades criativas para lidar com cada situação nova e que impõe que o mesmo seja, acima de tudo, inovador.

\section{PROFESSORES, AMBIENTES CRIATIVOS E TRANSFORMAÇÃO PEDAGÓGICA}

Hodiernamente, o mercado de trabalho exige que os profissionais tenham capacidade de operar com as novas tecnologias e conhecimentos que atendam às necessidades da sociedade, advindo daí a necessidade dos jovens serem preparados para a assunção de novos papéis (Mykhailyshyn, Kondur \& Serman, 2018), pois, a vantagem competitiva advém do conhecimento. Neste sentido, 
Silva-Guerra (2017) coloca em destaque o papel fundamental da educação quando assevera a coexistência de uma correlação direta entre a educação e a produtividade e ao defender 0 imprescindível investimento na capacitação do capital humano no fortalecimento do sector produtivo e no desenvolvimento das instituições e dos países. Esse processo requer professores criativos que formem alunos criativos (Oliveira \& Alencar, 2008). A importância destes profissionais é inquestionável no mundo atual, sobretudo no âmbito educacional, porque o progresso social encontra-se em estreita ligação com a educação. Isso envolve uma formação académica elevada dos professores do século XXI para alunos do século XXI, com mestrados científicos, doutoramentos e pós-doutoramentos, como eixos imprescindíveis para promover, motivar e gerar a cultura da investigação e gerar conhecimento e inovação (Silva-Guerra, 2017). A sua prática é a arma contra a corrupção, a pobreza, a tristeza, a preguiça e a cegueira perante o progresso (Siva-Guerra, 2017).

Com o mundo em mudança acelerada é de suma importância a adoção de uma dinâmica refletida dentro das fronteiras da escola, currículos e pedagogias (Kovacs, 2017). É consentâneo que as incontáveis evoluções tecnológicas, científicas e sociais têm imprimido uma enorme pressão para a mudança dos sistemas educativos, tanto no que diz respeito aos seus currículos e metodologias como nos seus espaços dinâmicos (Pedro, 2017). Para Kovacs (2017), os atores educativos principais, desde o governo nacional até aos professores das escolas recorrem frequentemente a respostas inovadoras, mas o resultado nem sempre é compreendido de igual modo por ambas as partes. Inovar na escola refere-se a redefinir todo o projeto de ensino, aprendizagem e processo de avaliação (Blândul, 2015). As intervenções inovadoras são uma tarefa complexa tanto para os governos como para as escolas (Kovacs, 2017). Inclui inovações pedagógicas, científicas, tecnológicas, infraestruturais, económicas, sociais, legais, administrativas, entre outras, sendo entendidas como um procedimento ou método que diferem significativamente da prática estabelecida e são usadas para aumentar a eficiência num ambiente competitivo. (Mykhailyshyn, Kondur \& Serman, 2018).

Dando relevância ao conhecimento que se detém sobre o processamento cognitivo da informação no cérebro humano, Pedro (2017) alerta para a importância de repensar e investigar acuradamente a forma como são organizados os espaços escolares, especialmente a sala de aula uma vez que 0 ambiente físico e os elementos que o constituem transmitem a funcionalidade do espaço e influenciam o comportamento e o bem-estar dos seus utilizadores, nomeadamente dos alunos atuais, sobretudo se for tomado em consideração o volume de tempo que, desde idades mais precoces, as crianças passam na escola. Também recomenda a necessidade de criação de espaços de aprendizagem designados 'salas de aula do futuro', constituídas em torno de diversas áreas de trabalho, organizadas com a intencionalidade de promoverem e potenciarem múltiplas e diversificadas competências, especificamente aquelas referidas como XXI-century skills, com diferentes tecnologias integradas nos espaços como as tecnologias de display e os dispositivo móveis como tablets, mobiliário diversificado, multifuncional e reconfigurável visando a garantia do bem-estar, conforto e ergonomia aos utilizadores. Nesta perspetiva, urge refletir de forma séria e organizada sobre 0 modo como o espaço físico da sala de aula se revela ajustável ao momento vigente, prevendo novos designs e configurações adequáveis às práticas pedagógicas, organizadas com vista à promoção de metodologias ativas de aprendizagem, facilitadoras da aprendizagem colaborativa, a diferenciação pedagógica e que rompam com as configurações tradicionais da transmissibilidade dos professores (Pedro, 2017) e, sobretudo, contribuam para desenvolver o potencial criativo e inovador dos alunos.

Khodabakhshzadeh, Hosseinnia, Moghadam, Ahmadi, (2018) verificaram que a criatividade é proeminente para os professores, tem uma relação significativa com a eficácia do ensino e impacto direto na aprendizagem e, mais importante, na vida futura dos alunos. Notaram, ainda, que a 
motivação dos professores também tem relação com a eficácia docente, por sua vez, a eficácia docente correlaciona-se com a criatividade e ética profissional. Os resultados deste estudo fornecem contributos para que professores e alunos reflitam sobre as próprias representações sobre a criatividade. Também Mikhailova (2018) defende que existem diferenças significativas nas manifestações criativas e inovadoras entre estudantes de diferentes idades o que a levou a apresentar recomendações visando a melhoria das tecnologias psicopedagógicas de apoio à formação do potencial inovador. Na sua aceção, o efeito educativo de uma pedagogia interativa conduz a distintos resultados tais como motivação, interação social, comunicação construtiva, memorização eficaz através da repetição e aplicação de conhecimentos na prática e da análise de situações problemáticas em grupo, envolvendo diferentes pontos de vista.

A imersão dos alunos nas condições de aprendizagem interativa, envolve-os na organização do seu autodesenvolvimento e dos seus pares, ajudando a analisar os erros e a encontrar soluções para superá-Ios. Isso cria uma oportunidade de interação em que 0 autodesenvolvimento acontece mergulhado na interação social. Neste sentido, importa realçar que o principal papel criativo e inovador é desempenhado pela tarefa pedagógica do professor que tem a missão de, através da interação coletiva, habilidades de autoconhecimento e auto potencial, habilidades de gestão do entusiasmo, cooperação, comunicação, desenvolver a identidade criativa, assente na identidade cívica, valores positivos e prioridades motivacionais de desenvolvimento pessoal e profissional dos alunos (Mikhailova, 2018). Importa, por isso, que desenvolvam habilidades que reflitam abertura, enfrentamento do risco, pensamento crítico, flexibilidade, sensibilidade, questionamento e não conformidade (Mullet, Willerson, Lamb \& Kettler (2016), sendo crucial para o progresso social uma prática docente inovadora que enfoque o conhecimento sob múltiplos paradigmas e procure potenciar aprendizagens significativas a partir de mudanças criativas e inovadoras.

\section{CONSIDERAÇÕES FINAIS}

Os fundamentos teóricos apelam a uma mudança paradigmática fundamentada na criatividade e na inovação a partir de um processo que valorize o potencial criativo discente e docente, estimule uma educação emancipatória, prepare os alunos para conviverem harmoniosamente em cenários adversos e desafiantes e contribuam para o progresso social. Isto é, realçam, sobretudo, que a criatividade e a inovação são aliadas e interdependentes e têm um papel fundamental no processo educacional. Neste sentido, não pode ser descurada a relevância dos ambientes educativos edificados em torno de espaços criativos, interativos, de comunicação, de investigação, de desenvolvimento e de partilha em que os fatores espaço, a pedagogia e a tecnologia se articulem e concorram para a potenciação da transformação pedagógica geradora de novos cidadãos que se almeja venham a contribuir para o progresso social.

É ponto assente que a educação se converteu na ferramenta fundamental para o progresso dos povos e dos países, que a mudança educacional só acontece mediante 0 envolvimento, a motivação, 0 ambiente criativo e inovador docente. As inovações têm de ser pensadas, geridas e realizadas pelo corpo docente. A sociedade exige novos professores para novos alunos, a laborar em ambientes educativos criativos e inovadores tendo como objetivo maior a melhoria da qualidade do ensino, partindo do pressuposto que a criatividade e a inovação docente, apesar de serem dois constructos multidimensionais que requererem muita investigação, parecem incluir a chave da mudança educacional e o progresso social desejado pela sociedade hodierna.

\section{REFERÊNCIAS}

Blândul, V. C. (2015). Inovation in Education - Fundamental Request of Knowledge Society. Procedia - Social and Behavior Sciences, 180(5), 484-488. 
Canário, R. (2005). o que é a escola? Um "olhar sociológico". Porto: Porto Editora. Carbonell, J. (2001). A aventura de inovar. A mudança na escola. Porto: Porto Editora.

Carvalho, A. D. (2002). A escola cultural como consciência crítica da sociedade global. In Manuel Patrício (Org.). Globalização e Diversidade. A escola cultural, Uma resposta. Porto: Porto Editora.

Cavalcanti, J. (2006). A criatividade no processo de humanização. Saber (e) Educar, 11, 89-98.

Correia, J. A. (1991). Inovação pedagógica e formação de professores. Rio Tinto: Edições ASA.

Gardner, H. (1984). Assessing Intelligences: A comment on 'Testing Intelligence without IQ tests'. The Phi Delta Kappan, 65(10), 699-700.

Gardner, H. (2001). Inteligências: Um conceito Reformulado. Rio de Janeiro: Objetiva.

Giroux, H. (1997). Os professores como intelectuais transformadores. Rumo a uma pedagogia crítica da aprendizagem. Porto Alegre: Artes Médicas.

Grande Enciclopédia Portuguesa Brasileira (n/d). Atualização, III, Lisboa/Rio de Janeiro: Editorial Enciclopédia. Limitada.

Grande Enciclopédia Portuguesa Brasileira (n/d). VIII, Lisboa/Rio de Janeiro: Editorial Enciclopédia. Limitada.

Khodabakhshzadeh, H., Hosseinnia, M., Moghadam, H. A. \& Ahmadi, F. (2018). EFL Teachers' Creativity and Their Teaching's Effectiveness: a Structural Equation Modelling Approach. International Journal of Instruction, 11(1), 227-238.

Kovacs, H. (2017). Unfreeze the pedagogies: inttoduction of a new innovative measure in Portugal. Revista Tempos e Espaços em Educação, 10(23), 73-86.

Mikhailova, O. B. (2018). Features of creativity and innovation development in students at secondary and high school. (IJCRSEE) International Journal of Cognitive Research in Science, Engineering and Education, 6(2), 11-19.

Min, T. \& Gruszka, A. (2017). The 4P's Creativity Model and its application in diferente fields. In Tang Min, Christian $\mathrm{H}$. Werner, Handbook of management of creativity and innovation: Theory and pratice, 3, Publisher: World Scientific Press, Editors, 51-71.

Mullet, D. R., Willerson, A. Kristen, N.L., Kettler, T. (2016). Examining teacher perceptions of creativity: A systematic review of the literature. Thinking Skills and Creativity, 21, 9-30.

Mykhailyshyn, H., Kondur, 0., \& Serman, L. (2018). Innovation of Education and Educational Inovations in Conditions of Modern Hogher Education Institution. Journal of Vasyl Stefanyk Precarpathian National University, 5(1), 9-16.

Nuñez, I. B., \& Santos, F. A. A. (2012). 0 Professor e a formação docente: a criatividade e as crenças educativas onde estão? Holos, 28(2), 148-165.

OECD (2009). Organization for Economic Co-Operation and Development. Education at a glance: 2209 indicators. Washinghton, DC: OECD.

Oliveira, Z. M. F., \& Alencar, E., M. L. S. (2008). A criatividade faz a diferença na escola: o professor e 0 ambiente criativos. Contrapontos, 8(2), 295-306.

Pedro, N. (2017). Ambientes educativos inovadores: o estudo do fator espaço 'nas salas de aula do futuro' portuguesas. Revista Tempos e Espaços em Educação, 10(23), 99-108.

Rajadel, N. (2012). A importância das estratégias didáticas em toda ação formativa. In: Suanno e Puiggrós (Org.). Didática e formação de professores: perspectivas e inovações. Goiânia: CEPED: Publicações PUC Goiás.

Rhodes, M. (1961). Na analysis of creativity. Phi Delta Kappan, 42, 305-310.

Riley, G. (2015). Creativity. Salem Press Encyclopedia of Health, 3.

Romo, M. (2008). Creatividad em los domínios artístico y científico y sus correlatos educativos. In 
M. F. Morais \& S. Bahia (Eds.), Criatividade: Conceito, Necessidades e Intervenção, Braga: Psíquilíbrios Edições, 65-90.

Runco, M. (2007). A hierarchical Framework for the study of creativity. New Horizons in Education, $55(3), 1-9$

Silva-Guerra, H. (2017). La innovación y educación: variables clave para la competitividade de las empresas. Revista Clío America, 11(21), 88-107.

Simonton, D. K. (1995). Personality and intelectual predictors of leadership. In Saklofske e Zeidner (Eds.), International handbook of personality and intelligence, New York: Plenum, 739-757.

Souza, K. P. Q. \& Pinho, M. J. (2016). Criatividade e inovação na escola do século XXI: uma mudança de paradigmas. RIAEE - Revista Ibero-americana de Estudos em Educação, 11(4), 19061923.

Suanno, J. H. (2013). Adversidade, resiliência e criatividade: uma articulação oportuna? In Suanno, Dittrich e Maura (Org.) Resiliência, Criatividade e inovação. Potencialidades transdisciplinares na educação. Goiânia: UEG: América.

Wechsler, n/d). Criatividade e Inovação: 0 impacto de uma educação estimuladora (Acesso 19/09/2018), retirado

https://www.google.pt/search?q=Criatividade+e+Inova\%C3\%A7\%C3\%A30\%3A+0+impacto+de +uma+educa $\% \mathrm{C} 3 \% \mathrm{~A} 7 \% \mathrm{C} 3 \% \mathrm{~A} 30+$ estimuladora\&oq=Criatividade+e+Inova $\% \mathrm{C} 3 \% \mathrm{~A} 7 \% \mathrm{C} 3 \% \mathrm{~A} 30$ $\% 3 \mathrm{~A}+0+$ impacto+de+uma+educa $\% \mathrm{C} 3 \% \mathrm{~A} 7 \% \mathrm{C} 3 \% \mathrm{~A} 30+$ estimuladora\&aqs=chrome..69i57.1644j $0 j 8 \&$ sourceid $=$ chrome\&ie=UTF-8

Wechsler, S. (2004). WAISS-III: Escala de Inteligência Wechsler para Adultos: Manual/David Wechsler. Adaptação e padronização de uma amostra brasileira: Elizabeth do Nascimento. São Paulo: Casa do Psicólogo. 
